\title{
Críticas postestructuralistas en las concepciones de los espacios geográficos
}

\author{
SPoststructuralistic reviews in concepts of geographical spaces
}

\section{Miguel Ángel Silva ${ }^{1}$}

\section{Resumen}

El presente artículo de reflexión indaga primeramente sobre las mutaciones que se han producido en el campo de las ciencias sociales y de la cultura en general, en contextos de modernidad y posmodernidad. El objetivo básico del artículo es apelar a concepciones postestructuralistas sobre el espacio y sobre el tiempo favoreciendo el estudio de las heterogeneidades y de las diferencias. Se plantean los distintos espacios de alteridad partiendo de la concepción de la geografía como espacialidades sociales que iluminen la teoría y que favorezcan los elementos críticos de las mismas. Se comienza con el análisis de los espacios del lenguaje, espacios del yo y del otro, espacios del lugar, espacios de la agitación, espacios de la experiencia y espacios de la escritura. Los resultados - teniendo en cuenta las problemáticas planteadas - son altamente provisionales y se constituirán mediante una continua resignificación conceptual discursiva que la geografía contemporánea nos pueda ofrecer.

Palabras clave: postestructuralismo, espacios alternativos, espacios del lenguaje, espacios del yo y del otro, espacios del lugar, espacios agitados, espacios de experiencia, espacios de escritura.

1 Doctor en Geografía. Profesor de Geografía, profesor titular ordinario, profesor asociado regular del Centro de Investigaciones Geográficas. Universidad Nacional de La Plata. Instituto de Geografía. Universidad Nacional de La Pampa, República Argentina. miguelangel.silva153@gmail.com 


\section{Abstract}

This article of reflection inquires first on mutations that happen in the field of social science and culture in general, in the context of the modernity and postmodernity. The basic objective of the article is to appeal to poststructuralists concepts about space and time favoring the study of heterogeneities and differences. We describe the different spaces of otherness, starting from the conception of geography as social spaces that make light up the theory and may help their critical elements. It begins with the analysis of the language spaces, spaces of myself and the other, spaces of the place, spaces of the agitation, spaces of the experience, and spaces of the writing. The results, taking into account the issues raised, are highly provisional and will be constituted using a continuous discursive conceptual resignification that the contemporary geography can offer.

Keywords: poststructuralism, alternative spaces, language spaces, spaces of self and other, spaces of the place, spaces of the agitation, spaces of experience, spaces of the writing. 


\section{Introducción}

El presente artículo tiene la intención de reflexionar y debatir sobre perspectivas que hasta estos momentos han sido parcialmente eludidas por la academia geográfica latinoamericana.

Esta circunscripción y la elección del tema: Críticas postestructuralistas en las concepciones de los espacios geográficos, se encuentran contextualizados en una serie de debates mucho más inclusivos, que, más allá de la consabida y tradicional concepción de paradigmas de origen kuhniano, enriquecen como panorama contenedor los niveles de tensión y análisis crítico de los mismos.

La relación dialéctica modernidad-posmodernidad sería el eje estructurante donde se desarrollaría la irrupción de los cambios en la cultura contemporánea, ya que a través de la misma se han tejido y se enhebran y entroncan los distintos discursos que le dan sentido y direccionalidad al pensamiento contemporáneo.

A lo largo de la historia de la geografía, el desarrollo de una racionalidad dominante de carácter teórico o instrumental es la que ha prevalecido a la hora de conceptualizar el espacio como objeto de estudio de la geografía, como han señalado algunos geógrafos que se han dedicado a la historia crítica del pensamiento geográfico: Capel (1981), Gregory (1978, 1998), Ortega Cantero (1987), Unwin (1995), Ortega Valcárcel (2000), Thrift (1996). Si bien, ello ha sido evidenciado en la geografía del análisis locacional y parcialmente en las corrientes perceptuales y comportamentales hasta las dialécticas críticas, en escasas oportunidades se ha indagado en el ámbito de la geografía latinoamericana la construcción de otras espacialidades alternativas que cuestionen la validación de dichas espacializaciones racionalistas. La articulación de lo social y lo geográfico, en infinidad de oportunidades fue tratada como si el mundo de lo social fuera ajeno al geográfico, casi siempre conservando una actitud discursiva excesivamente binaria - independiente - del talante crítico que se le haya otorgado. Es decir, que el binarismo que focaliza el yo cartesiano siempre ha sido el centro de la construcción del discurso que se generó a través y alrededor del mismo. Lo que se pretende ahora es explorar, cuestionar y desmontar ese yo ordenador, ese yo organizador tanto como praxis, tanto como metáfora, pero no acudiendo a lo "otro" como antípoda, que ocluye, y no permite la presencia de "otros" que se manifiestan por medio de discursos, sujetos, conceptos teóricos, etc.

La idea central para la concepción de estas otras espacialidades que se desarrollarán a continuación, se fundamenta en la anterior definición de lo social como sustantivo y constitutivo de hacer geografía; pero aquí hay que hacer notar y marcar como perentorio que ese ethos social debería ser un ethos que se traduzca en términos más poéticos e imaginativos-críticos o en prácticas sociales que generen multiuniversalidades y no solamente universalidades. 
Estos tipos de análisis epistemológicos abordan la articulación entre lo histórico, social, cultural y geográfico, ya que contienen un potencial crítico e inevitablemente desestabilizador, como estrategia para definir esas "otras" formas de pensar, concebir y actuar en los espacios geográficos.

El objetivo del artículo es presentar un panorama epistemológico de las tendencias postestructuralistas, las que - predominantemente- desafían las discursividades racionalistas y universales-estáticas de los discursos de las ciencias sociales en general y de la geografía, en particular.

Se ha elegido el texto Thinking Space, como un lugar para explorar dichas tensiones epistemológicas y metodológicas y como ensayo creativo para pensar la geografía en direcciones alternativas a lo planteado por el statu quo.

Los capítulos que son tratados en el texto corresponden a pensadores, tales como: Wittgenstein (1961), De Certeau (1982), Derrida (1967), Bakhtin (1981), Foucault (1976), Deleuze y Guattari (1998), Virilio (1997), Latour (1993), Serres (1994), Said (1995), Fanon (1961), Benjamin (1982), Lefebvre (1974). Merecen un capítulo especial y una buena parte son analizados por geógrafos británicos: Gregory, Doel, Philo, Merrifield, Savage. Los primeros son los referentes por los cuales se pueden interpretar seis tipos de especialidades.
En la introducción al libro, en sus dos editores: Nigel Thrift (2000) y Mike Crang (2000), ya se pueden evidenciar sus propuestas, sus preocupaciones y sus ocupaciones en tanto geógrafos que poseen una mirada interpeladora, no solo del concepto espacio, sino de la vida misma en cuanto objeto de estudio y sus despliegues, en tanto concreciones materiales y simbólicas.

Novedosos planteos ante la geografía convencional y también para los campos de relaciones extradisciplinarias, sea del área lingüística, comunicacional, psicoanalítica o estética, ética o cognitiva.

Evidentemente, las lecturas y la concreción de este libro sirvieron de plataforma básica para la conceptuación de las teorías no representacionales que posteriormente elaboraría el mismo Nigel Thrift (2008), con elementos ligados a las representaciones, al poder, a las identidades, al lenguaje y las prácticas sociales, al tiempo y a las performatividades en la vida social.

Las seis espacialidades enumeradas y desarrolladas en la introducción de este libro, son:

a) Espacios del lenguaje.

b) Espacios del yo y del otro.

c) Espacios del lugar.

d) Espacios de la agitación.

e) Espacios de experiencia.

f) Espacios de escritura. 
Las dos primeras nos remiten a planteamientos teóricos que, aún hoy día, transitan las ciencias sociales, y las otras cuatro tienen puntos referenciales disciplinarios más concretos.

La metodología para desarrollar este artículo fue la hermenéutica crítica, en tanto comprensión y análisis de la introducción y de los discursos textualizados que constituyen el cuerpo central del libro.

En otras palabras, nos encontramos ante una metodología fuertemente interpretativa que se corresponde evidentemente con dichos planteos hermenéuticos básicos.

\section{Espacios del lenguaje}

Siempre ha existido una conexión entre el lenguaje y el espacio, pero con distintas modalidades. En principio, el lenguaje es el gran mediador entre el pensamiento prístino y el mundo, $\mathrm{y}$, de esta forma, como el lenguaje puede ser espacializado, como el espacio puede ser textualizado.

Podríamos decir que se constituyen en el antecedente de las geografías estructuralistas y postestructuralistas que, como corrientes teóricas, no solo comienzan en la lingüística, sino que se expanden a la antropología, la física, la neurobiología, etc.

Las ideas del lingüista suizo De Saussure (1945), podrían ser las primeras en las que abrevar a través de la lingüísti- ca estructural, donde no se rastrean los cambios del lenguaje a lo largo del tiempo y del espacio cultural. Para De Saussure (1945), cobra importancia central un espacio lingüístico para definir su atemporalidad en concordancia con el modelo sincrónico.

Es decir, la preeminencia del lenguaje en un tiempo determinado y no a lo largo del tiempo (diacrónico). Si bien el modelo saussureano es estático en sí, es de referencia espacial, y fundamentalmente en la concepción del significado y del significante y la red semiótica en la cual se relacionan entre sí los elementos del lenguaje.

Estas concepciones influenciarán en la deconstrucción de Derrida (1967) y también en uno de los psicoanalistas más importantes del siglo $\mathrm{XX}$ : Lacan (1992).

El trabajo lacaniano se centralizó en la constitución de un universo estructural significante maestro, un principio ordenador y legislador: en este caso, la ley del nombre del padre.

La relación de lo real con el lenguaje es una exterioridad inarticulada y traumática que no se corresponde con el universo simbólico. Para Lacan, el lenguaje es un espacio intricado y anudado de relaciones complejas donde se registran lo simbólico, lo imaginado y lo real.

Deleuze (1998), sin embargo, se aleja del lenguaje como representación y se acerca a la acción, pero como creadora de efectos y no, como supondría es- 
perarse, como representación teatral. Ciertamente aquí el aporte de Heidegger (1951) es importante, al considerar el espacio más que como un límite, como una creación de lo que encierra, donde tiene más que ver con el hacer que con el conocer.

Otro punto interesante de estos espacios del lenguaje nos remite al lugar que ocupan el enunciado y el lugar de enunciación. Aquí las referencias nos llevan al teórico ruso Mijail Bakhtin (1981), que desarrolló su tarea a lo largo de todo el siglo XX hasta su fallecimiento en 1975, y quien nos propone dos conceptos centrales en su teoría literaria: la heteroglosia y las unidades del habla.

La noción de heteroglosia implica a los lenguajes operando en plural y entre personas y lugares, y donde se evidencia la particularidad de considerarlos como evolucionan.

Desde el segundo punto de vista, Bakhtin (1981) ubica al lenguaje tanto en el espacio como en el tiempo, mediante el cronotopo como el campo histórico del dominio de formas particulares del lenguaje. El lenguaje aquí está insertado en el contexto de unidad de habla, entendiéndose en tres términos: el emisor, el destinatario y la relación existente entre ellos. Donde existe una relación incompleta entre los sistemas simbólicos con la acción de lo social, donde dos emisores no tienen el mismo parecer, donde el emisor y el público ven la misma práctica comunicativa pero de distintas posiciones. Bakhtin nos remitía al principio dialógico de la razón y por lo tanto de la comunicación. Entonces el lenguaje está ligado a los tiempos y a los espacios en acción. Esto nos lleva a dos preguntas básicas: ¿Qué rol juega el espacio en la construcción del pensamiento y del lenguaje? ¿Existen espacios que se despliegan, y con qué efectos? La presencia de los espacios del yo y del otro podría explicar estas preguntas.

\section{Espacios del yo y del otro}

En la historia de las ideas existen perspectivas sobre la construcción del yo que, en algunas épocas, fueron altamente hegemónicas, con planos muy interesantes acerca de su pertinencia actual o de su real o aparente desaparición. Ortega Valcárcel (2000)

La construcción del yo moderno evidentemente reconoce - con independencia de las teorías biologicistasuna fuerte impronta cartesiana: en la conocida separación mente y cuerpo. Hubo deliberados intentos por estructurar una unidad de ese yo, desde ópticas vitalistas que tienen fuertes connotaciones heideggerianas. Thrift (1996), Díaz (2007)

También la cuestión del yo tiene mucho que ver con Foucault, acerca del yo como cuerpo administrado, entrenado y disciplinado. En relación directa con Foucault (2002), otros autores piensan que el cuerpo es un artefacto sociocultural donde la corporalidad en sí mis- 
ma se reproduce desde lo psíquico, lo social, lo sexual y lo representacional (Grosz, 1995). La cultura construye así un orden biológico a su propia imagen.

El individuo moderno corresponde y está relacionado con la textualización del yo, con el surgimiento de diarios y autobiografías. Por ejemplo: los estudios de la historia de la vida privada de Ariès y Duby (1992) han brindado sugestivos aportes.

Posteriormente, el individuo es reestructurado en tiempo y espacio, definidos como existencias particulares, pero existencias tecnologizadas y ciertamente inscriptas en límites disciplinarios y en procesos de dominio y autocontrol. El yo moderno fue creado utilizando tecnologías mediadoras, conectando a la gente en tiempos y lugares distintos. Thrift y Crang (2000)

Filosóficamente, aquí el yo se crea por un-estar-en-el-mundo. Las fronteras del yo no son el límite, sino que refuerzan ese sentido del yo.

Se podría mirar un yo espacial moderno a través de estas lentes de individualidad práctica y espacializada. Por ejemplo, la unificación y fragmentación de ese yo mediante nuevos medios de transporte, comunicaciones y los medios masivos de comunicación y tecnología. Esto fue estudiado por Virilio (1997) en sus tratados comunicacionales en la década del 90.

Pero habría que acotar que esta concepción del yo espacial implica nuevas es- calas y funciones. El género, la clase y las circunstancias históricas modulan la expansividad del espacio imaginario.

Aquí existe un punto neurálgico, pues el proceso de individualidad espacial se ha aumentado con los modelos dualistas del "yo" y del "otro", que sustentan una serie de imaginarios territoriales favoreciendo territorios de autoidentidad contra una alteridad radical y exótica creando fuertes tensiones culturales. Thrift (2000)

Ciertamente, esta situación desembocó en Occidente en la creación y legitimación de derechos y teorías universalistas, ellas se basaron en el no-Occidente como escenario de apoyo material y simbólico. En este sentido, el filósofo turco Castoriadis (1975), en su primera época, establece que la mirada teórica solo podía leer lo que estaba escrito en término de la misma y no admitía espacios de alteridad.

Esto nos lleva indefectiblemente a considerar las influencias del pensamiento poscolonial que ha mutado de intentar descolonizar las autoidentidades de quienes anteriormente eran gobernados por poderes occidentales, a intentar deshacer el legado colonial en categorías del pensamiento occidental.

Las categorías e ideas del pensamiento occidental moderno, entonces, deben relocalizarse desde lo geográfico, y sus pretensiones de universalidad necesitan circunscribirse y localizarse. Esto, a su vez, implica una crítica al sujeto conocedor y trascendente que lleva las prác- 
ticas coloniales a la órbita teórica y se encierra en una lógica de dominio.

El cartógrafo Tom Conley (1996) trabajó esta situación en las representaciones cartográficas en los mapas cordiformes basados en la analogía humanista del cuerpo y del mundo.

Esta visión implica una crítica a la concepción cartesiana de la espacialidad y, en cierta medida, a la concepción estética de un pintor como por ejemplo el holandés J. Vermeer, en este caso a través de su célebre cuadro El geógrafo. ¿Por qué?

Por un lado, el cartesianismo con su trascendencia epistémica que era una técnica compleja de poder, era un medio para el observador de legislar lo que constituía la verdad receptiva (Crary, 1990). Así, la mente del investigador funciona como un espacio interior y la percepción y el pensamiento se interpretan como cuasiobservables. El pintor holandés J. Vermeer, del siglo XVII, con su cuadro El geógrafo, nos demuestra ciertamente su función moderna, en que el sujeto privado aislado, encerrado en un espacio doméstico donde el conocimiento sigue un modelo de representación visual que objetiva el mundo en que el observador se encuentra, en un vértice de un cono de visión y que se constituye en una forma excepcional de dominio. Thrift (2000)

Se corre el riesgo entonces de identificar la producción del mundo como imagen adoptando la posición de sujeto, evadiendo diferentes pensamientos acerca de los espacios del conocimiento y del deseo, por ejemplo.

Por ello es que se proponen modos de conocimiento no figurativos, las teorías del actor-red, las teorías de las prácticas, los conocimientos performativos y los espacios de la teoría en diálogo. (Thrift \& Crang, 2000)

Es interesante notar que el concepto de interacción dialógica nos marca la inserción del sujeto en los lugares, pero las tecnologías visuales modernas desplazan al observador, para convertirlo a él en parte del campo de la visión. Entonces, el espacio del conocimiento no se automantiene, pues, al contrario, genera diferencias. Estas diferencias no se producen en abstracto, sino que se resuelven en espacios concretos. Por ejemplo: los espacios concretos de la modernidad.

\section{Espacios del lugar}

Para interpretar los espacios del lugar es imprescindible conectarnos con la teoría social y con algunos de los aspectos de las teorías urbanas. Se parte como ejemplo ilustrativo de las situaciones metonímicas de dos ciudades: París, como metonimia de la modernidad, y Los Ángeles, como metonimia de la posmodernidad, tal como lo plantea Edward Soja $(1989,1996)$ en sus respectivos libros: Postmoderns Geographies y Thirdspace: Journeys to Los Angeles and other real and imagined places. 
París constituiría la metonimia del lugar de la modernidad, puesto que es considerada como la ciudad de la imaginación y de la teoría o, al menos, como una imaginación teórica. También porque gran parte de los cientistas sociales tratados en este trabajo realizaron sus investigaciones en esta ciudad. La mayoría de ellos que pensaron a través de los lugares y la imaginación de los lugares que producen teoría.

Existirían tres elementos para considerar a París como un lugar vivo y concreto: 1) la posición de París en el campo de la producción artística y de otras formas culturales. No sería posible referenciar a París sin la presencia de los poetas simbolistas como Rimbaud o Baudelaire, sin los impresionistas como Manet, Toulousse-Lautrec, etc; sin los escritores tales como Emile Zola o Víctor Hugo. Pero muchos estudiosos relacionan la experiencia artística parisina con la sexualidad y el espacio urbano.

Ya Walter Benjamin (1982), inspirado por la poesía de Charles Baudelaire, nos hablaba de París como la capital del siglo XIX y como la ciudad embrionaria de movimientos artísticos de la modernidad. En síntesis: nos hablaba del prototipo del hombre moderno: el flaneur. (Baudelaire, 2009)

Se asocia el concepto de flaneur con un tropo de las prácticas artísticas, intelectuales y urbanas con su legado de masculinidad, consumo vital, objetos transformados en productos ( $\mathrm{y}$ en la esfera pública sexualizada, feminizados). Aquí pareciera que la ciudad de París tiene una función regulatoria del espacio sexualizado muy distinta a Londres, Madrid o Berlín, especialmente en la reglamentación de la "vida nocturna".

2) La adaptación de estas prácticas estéticas es la problemática de París como ciudad textualizada. Un estudioso de la cultura: Prendergast (1992), analiza el mapeo de paisajes a páginas y en ese sentido, es tanto lo que se ha escrito sobre París con respecto a los desplazamientos y a las teorías del viaje, que cuando investigamos sobre los escritores refugiados pensamos no solo en biografías, sino en verdaderas geografías. París se constituye así en una ciudad que emerge de los intersticios de sus propias ruinas. Recordemos los textos de Michel de Certeau (1984) o los del mismo Walter Benjamin, cuando compara su infancia en Berlín y como trae del pasado imágenes al presente en su obra emblemática: El Proyecto Arcades (Das Passagen-Werk). (Benjamin, 1982).En este sentido,para Benjamin:París es una de esas ciudades cuya grandeza emerge desde los intersticios de sus ruinas del pasado. Olalquiaga (1992)

3) Del análisis semiótico se puede extraer una urbanidad que refleje las prácticas de la vida cultural y de la forma en que estas se desterritorializan como universales y se reterritorializan reflexivamente como una buena ciudad.(Thirft y Crang, 2000)

La presencia y crecimiento de cafés a finales del siglo XIX (24000 cafés), como también los cambios nocturnos en las calles. París es una ciudad central cuya 
historia se puede elucidar a lo largo de una historia de límites concéntricos. El reconocimiento del París desconocido, las importancias étnicas otorgadas por algunos autores: Maspero (1994) o Augé (2000) a los banlieues (barrios periféricos), que se han convertido en sitios marginales, de movimientos anclados en un lugar que toman relevancia actual en la teoría o en el arte.

Es mucho más fructífero considerar a la periferia desde estas perspectivas, desde abajo y no con un interés para generar homogeneidades urbanas, sino tratar las formas estéticas de tal manera para que vislumbren multiplicidades; es lo que llamaría el jesuita Michel de Certeau (1984): heterologías.

Por ello, París es tomada como emblema de la modernidad y su vida moderna se lee a través de un relato de velocidad, como un verdadero agente devastador de una orientación espacial que reclama y reconoce prácticas estéticas.

\section{Espacios agitados}

Las figuras de espacios agitados se deben a Bruno Latour (1997), quien mediante sólo unas narrativas clave, que luego proveen toda la acción, genera un tropo radicalmente constituido.

Una de las narrativas más importantes es la que se refiere a la compresión temporo- espacial: Bauman (2000), Harvey (1995), Virilio (1991), Jameson (1996). Esta es una narrativa que tuvo y tiene una amplia exposición en los discursos geográficos, culturales y sociopolíticos de finales del siglo $\mathrm{XX}$ y principios del XXI.

La compresión temporo-espacial presenta dos situaciones que se excluyen mutuamente: es importante, a la vez que se torna menos importante. Aquí los viajes y las comunicaciones tienen un rol fundamental, y la velocidad que han adquirido ha atravesado las fronteras nacionales a través de porosidades materiales por un lado, y a través de flujos informacionales, por el otro, Castells (1997), que puede producir una disolución total del espacio, generar un espacio isocrónico, un espacio como dimensión perdida, en palabras de Virilio (1997). Sobre el viejo espacio territorial, surge un nuevo espacio cibernético. La noción de que vivimos en un mundo acelerado se ha convertido en un recurso para las culturas occidentales, como una forma de generar nuevas identidades y de hacer nuevas metáforas.

Si bien la aceleración alimenta y se alimenta de la narrativa globalizadora, la que sin embargo produce una propensión a trabajar la idea de diferencia. De allí que es más importante en la vida contemporánea la variedad cultural de las sociedades, que la variedad de culturas en la sociedad.

En el proceso de la expansión de redes, las culturas se arremolinan, se mezclan, comienzan a gestarse nuevamente. También la globalización está poniendo en tela de juicio las nacionalidades fijas, despojando la idea de culturas herméticas. Por ello, no es extraño que la 
globalización haya producido innumerables metáforas espaciales. Metáforas de identidades y de pertenencias que son abiertas, basadas en puntos de contacto, en hibrideces, zonas fronterizas, y que, ciertamente, cuestionan la vieja dialéctica de Oriente-Occidente, de lo familiar y de lo extraño, de lo uno y de lo otro, pergeñando una mezcla cultural que tiende a deslegitimar la idea de exotismo cultural tan típicamente modernista (esto se puede observar no solo en la realidad, sino también por ejemplo en el cine etnográfico que había sido elaborado siguiendo estas pautas de exotismo social y cultural).

\section{Espacios de experiencia}

La idea de espacios de experiencia genera controversias acerca de la constitución fenomenológica del yo, es decir, cómo podemos hablar hoy de espacios experimentales subjetivos cuando el yo considerado como el cuerpo parece difuminarse y debilitarse.

Por esto es que la noción de experiencia tiene que ser compartida con otras corrientes de pensamiento que involucren y relacionen las cuestiones de la movilidad. Una de estas corrientes es la que postula el paso de la noción de cuerpo, no como centro de percepción, privilegiado, sino como personificado, donde lo carnal en algunas oportunidades se relaciona con el mundo y llega a interactuar con otros campos, miméticamente o de otras formas. En la teoría de actorred, el pensamiento siempre viene muy equipado, rodeado de un vasto aparato de artefactos, que no son incidentales, sino que están mediados por la propia producción de los objetos.

La experiencia y el pensamiento siempre han estado asociados a la calma, pero con la predominancia del viaje hay que dotarla de nuevas experiencias para pensarla en esos términos. Y para finalizar, la experiencia implica un modelo de escritura como un modo de inscripción que mejor pueda expresar, mediante nociones derrideanas de indicio y aplazamiento, la ilusión de la propia presencia, el aquí y el allí del viaje y la necesidad de producir modelos que puedan hacer algo diferente. (Thrift \& Crang, 2000)

Ciertamente cada una de estas literaturas pone énfasis en la práctica, pero en una práctica distribuida e impulsada a la acción mediante la conexión en espacios que están representados como un verdadero enjambre de movimientos y contramovimientos.

Tres escritores trabajaron sobre estas perspectivas: Derrida, Deleuze y Serres. El primero a través de la deconstrucción, el segundo a través del pensamiento rizomático y el tercero asociado al ya mencionado Bruno Latour. Lo que quiere Derrida con la deconstrucción, es minar dentro de los textos la lógica de la oposición del binarismo, tan presente en la mayoría de ellos. Pero la deconstrucción derrideana es criticada precisamente por alejarse de la construcción y existencia contradictoria de la vida en sentido amplio, y su deconstrucción 
trasladada al texto pareciera que escribe sobre la nada.

En el caso de Deleuze (1988), la vida es un poder impersonal, no orgánico, que va más allá de cualquier experiencia vivida. Para Deleuze y su "geofilosofía", el espacio es una dimensión crucial que requiere nuevos territorios conceptuales: nuevos espacios afectivos y perceptivos (artísticos), nuevos espacios de imágenes (pintura, cinematografía), nuevos espacios de sonido (música). Ciertamente que Deleuze, en el tratamiento del inconsciente, lo referencia a la construcción de los mapas, donde -entre otras tantas cosas - los mapas deberían construirse no por medio de trayectorias, en extensión, sino en intensidades, lo que colma el espacio como una forma de conversión.

Ligado parcialmente a la anterior perspectiva de Bruno Latour, se encuentra el pensamiento de Serres (1994), en el que la experiencia es una cualidad móvil en la cual el tiempo y el espacio se encuentran realizados por el trabajo de operadores comunicativos. Tanto tiempo, como espacio, constituyen una "diversidad plegable múltiple”, de ahí su interés por el viaje y por las representaciones cartográficas. Para él, dicho espacio móvil es sólo factible por los flujos y de él emanan imágenes para el viajero, en este caso un geógrafo que las tiene que traducir siguiendo las connotaciones de movilidad para poder advertirlas en sus desplazamientos.

\section{Espacios de escritura}

En principio: ¿Será la escritura el problema esencial de la especialización?

Thrift (2000) considera que en las ciencias sociales y en las humanidades se puede observar cierto retorno a las "representaciones". Este autor avanzará posteriormente a la escritura de este libro que analizamos Thinking Space (2000), hasta generar las teorías no representacionales donde la escritura reclama "performatividad" como una manera de transmitir planos emocionales y afectivos, como una forma de registrar los sentidos.

En la época que escribe Thrift, apela a estas representaciones textuales basándose en el ya mencionado Derrida, para entender una concepción en el estímulo del "juego" de la semiosis mediante el poder comunicativo del intertexto, la escritura conjunta de rastros y una búsqueda de enredos productivos que han desafiado la lucha espaciotemporal del lenguaje.

Judith Butler (1993) piensa el discurso como un juego de sustitución, donde un signo es más que un signo en sí: "es un signo de" o "un sustituto para". Desde la literatura en general, las obras de Joyce (1995) o Beckett (1952) transforman al lenguaje en representación y la escritura se concibe como un espacio por el cual viajar y con el cual negociar, $\mathrm{y}$ esto se encuentra presente hasta en ciertos aforismos de Nietzsche (2003) o Wittgenstein (1961). 
Pero la obsesión de la escritura como espacio tiene algunas consecuencias. Una vez que la escritura se convierte en espacio, se generan paralelismos con otras formas espaciales, con redes de comunicaciones y tecnologías de la información, con viajes y transportes, con diagramas o pantallas (como recursos) que mezclan la escritura con los espacios de la ciencia. Esto es lo que sucede con los espacios del caos que son tanto científicos o generalmente culturales, como los piensa Bruno Latour (2007).

Por ejemplo, Livingston (1997) intenta estudiar a través del caos una lógica que funciona en las formaciones históricas y culturales del Romanticismo y de la postmodernidad.

En segundo lugar, los textos pueden ser considerados como una especie de geografía corpórea, donde se concentra en el mecanismo paratextual de la autoría: tapa, nombre del autor, título, dedicatoria, epígrafe, prefacio, notas al pie, de-

Cuadro sinóptico metodológico

Tipos de espacios finiciones, glosario, etc. Es decir, que existe una ubicación. En tercer lugar, los espacios en el texto son espacios de experimentación, que intentan escribir más allá de las formas corrientes de textualidad (Thrift \& Crang, 2000). Deben contemplar evocaciones, metonimias, subjetividades, citas y vueltas a citar, y resultantes. Lo que se busca es escribir sobre mapas literarios. Para Moretti (1998), debería considerarse el mapeo de los espacios de escritura como un método en y de sí mismo.

Para finalizar el núcleo expositivo del artículo, se brindará un cuadro sinóptico con las metodologías que en algunos casos son específicas de cada tipo de espacios, pero que en otros, se complementan. Pero haciendo la salvedad que todas ellas se alejan de las metodologías positivistas y empiristas racionalistas, con el objetivo de desentrañar la espacialidad social con los siguientes encuadres metodológicos:

Encuadre metodológico
Espacios del lenguaje
semiótico-cronotopo
Espacios del yo y del otro
psicoanalítico-imaginario
Espacios del lugar
vivencial-existencial-metonímico
Espacios agitados
teorías del actor-red.
Espacios de experiencia
deconstrucción-rizomático
Espacios de escritura
deconstrucción-metonímico 


\section{Conclusiones}

En el artículo se han tratado nuevas especialidades que indiscutiblemente nos encaminan a establecer una serie de conclusiones que se relacionan con cuestiones que son de orden epistemológico, metodológico, filosófico, científico y geográfico, en sentido estricto.

En primer lugar, desde el punto de vista epistemológico se cuestionan las filosofías racionalistas y las filosofías del yo como ordenadoras y legitimadoras del statu quo científico tradicional. Ello supuso indagar acerca del "giro cultural" o giro lingüístico que se ha producido en las dos últimas décadas del siglo XX.

En cuanto al conocimiento en general, se han puesto en tela de juicio los criterios de validación y hasta los presupuestos éticos que conlleva la investigación científica teórica y aplicada. Todo ello supone un cambio en las formas de difusión de la realidad constitutiva de los procesos con los que habitualmente nos encontrábamos abocados en la tarea intelectual (comprensión, explicación, descripción, crítica, etc.).

$\mathrm{Al}$ desplazar ese yo racionalizador, entran en juego nuevas percepciones e intelecciones, nuevos posicionamientos en las relaciones cognitivas y hasta en las valorativas, generando un campo fértil que debe ser debatido porque atañe directamente a nuestra tarea diaria como geógrafos. Es importante aclarar que tampoco existe consenso acerca de los efectos críticos que pueden generar estos discursos sobre la posmodernidad.
Para algunos intelectuales, la cuestión posmoderna implica una red de enmascaramientos ideológicos que anulan la criticidad de formas de pensamiento modernista ya consagradas. Para sus defensores, por el contrario, lo posmoderno implica una apertura a las otredades y a las alteridades, desmitificando los discursos legitimadores de la cultura occidental contemporánea. De esta forma se accede a ciertas formas de relativismo cultural que actuarían como fuentes de resistencia a los mecanismos opresivos y coercitivos e impuestos por el pensamiento racional, ordenador y modernista.

En segundo lugar, refiriéndonos a las concepciones de las nuevas especialidades, es innegable que los nuevos procesos de territorialización y desterritorialización supondrían nuevos posicionamientos no solo empíricos, sino teóricos.

Esta situación de las nuevas territorialidades y de qué forma los procesos de aceleración de los medios de comunicación, la constante individualización y la irrupción de sofisticadas tecnologías tuvieron y tienen efectos positivos, pero también negativos sobre las conceptuaciones del espacio. Las ideas que aquí toman fuerza son, por un lado, el tratamiento que otorgamos a los espacios de la virtualidad y por otro lado, también se pueden observar las fragilidades y arremolinamientos y porosidades culturales, políticas, sociales, económicas y espaciales. Parecería que de esta forma comprendemos que los procesos de espacializaciones no quedan fijos en 
sus conformaciones y en sus dinámicas; contrariamente, existen fracturas y pliegues de dichas espacializaciones, como afirma la geógrafa británica Doreen Massey (2005).

En tercer lugar, las propuestas de Thrift y Crang resultan atractivas sobre las posibilidades de trabajar o deconstruir (en lenguaje derrideano) la cuestión espacial del texto, rescatando planos vivenciales, biográficos o emocionales, permitiendo la acción dialógica entre los unos y los otros, recuperando formas semióticas escasamente exploradas en el seno de las lecturas de la geografía convencional.

En cuarto lugar, las corrientes postestructuralistas junto con las deconstruccionistas, aunque francesas en su origen, tuvieron una aceptabilidad razonable en la academia estadounidense y británica, y junto a otras facilitaron la irrupción de los estudios culturales (género, minorías sexuales, minorías religiosas, etnias,) y del poscolonialismo, el nuevo tratamiento de los viajes como formas de representación, el estudio de las mentalidades de los viajeros, las tensiones y apropiaciones de los nuevos espacios descubiertos, etc.

En quinto lugar, dado que se trata de espacios de múltiples lecturas sociales, culturales y políticas no convencionales, de los que también podría rescatarse el estudio de las subjetividades subalternas (con autores tales como Bahba (2010), Spivak (2000), Beverley (2004), Mo- reiras (2001), etc.), que se relacionan con los estudios poscoloniales, los que a su vez están ciertamente influidos por la deconstrucción. Aunque es necesario advertir que el rescate de estas ideas sobre "lo subalterno" está siendo cuestionado por otras corrientes de pensamiento más universales y totalizadoras (por ejemplo: el marxismo), sobre la recepción y las lecturas que de las mismas se pueden llevar a cabo en Latinoamérica.

De las anteriores conclusiones más generales, arribamos a una conclusión sustantiva y específica, producto del análisis hermenéutico realizado sobre dichas espacialidades interpretadas en el artículo, como se planteó en el objetivo central: marcar diferencias y propender a la búsqueda de heterogeneidades sociales, culturales, histórico-geográficas y políticas.

En concomitancia con esta conclusión a la que se llega, las propuestas de estas nuevas espacialidades, nos presentan una serie de pistas o caminos sobre cómo tensar el estudio de la geografía, ya que reinterpretan, reelaboran y cuestionan lo disciplinariamente establecido. Por ello - lejos de hacer una crítica ortodoxa o lineal- sería más enriquecedor desplegar un arsenal de esfuerzos que develen los mecanismos subyacentes que existen en teorías, propuestas y prácticas geográficas, y se considere a las mismas como un laboratorio experimental y vivencial desde donde iniciar y transitar la crítica académica cotidiana. 


\section{Literatura citada}

Ariès, P. \& Duby, G. (1992). Historia de la vida privada. Madrid: Taurus.

Augé, M. (2000). Los no lugares. Espacios del anonimato. Introducción a una antropología de la sobremodernidad. Barcelona: Gedisa.

Bahbha, H. (2007). El lugar de la cultura. Buenos Aires: Manantial.

Bakhtin, M. (1981). The dialogical imagination. Austin: University of Texas Press.

Baudelaire, C. (2009). Arte y modernidad. Buenos Aires: Prometeo.

Bauman, Z. (2000). Modernidad líquida. México: Fondo de Cultura Económica.

Beckett, S. (1952). Esperando a Godot. Buenos Aires: Losada.

Benjamin, W. (1982). Das Passagen-Werk. Frankfurt a. M.: Suhrkamp.

Beverley, J. (2004). Subalternidad y representación. Madrid: Iberoamericana Vervuert.

Butler, J. (1993). El género en disputa. Feminismo y la subversión de la identidad. Buenos Aires: Paidós.

Capel,H. (1981). Filosofía y ciencia en la geografía contemporánea. Barcelona: Barcanova.

Castells, M. (1997). La era de la información. Vol. I. Madrid: Alianza Universidad.

Castells, M. (1998). La era de la información. Vol. II. Madrid: Alianza Universidad.

Castoriadis, C. (1975). La institución imaginaria de la sociedad. Vol. I y II. Barcelona: Tusquets.

Conley, T. (1996). The Self-Made Map: Carthographic Writing in Early Modern France. Minneapolis: University of Minnesota Press.

Crary, J. (1990). Techniques of the Observer. Cambridge, MA: MIT Press.

Deleuze, G. \& Guattari, F. (1988). Mil mesetas. Capitalismo y esquizofrenia. Valencia: Pre-Textos.

Derrida, J. (1986). De la gramatología. México: Siglo XXI.

Derrida, J. (1989). La escritura y la diferencia. Barcelona: Anthropos.

De Certeau, M. (1984). The Practice of everyday life. California: California University Press.

De Saussure, F. (1945). Curso de lingüística general. Buenos Aires: Losada. 
Díaz, E. (2007). La posciencia. El conocimiento científico en las postrimerías de la modernidad. Buenos Aires: Biblos.

Fanon, F. (1961). The Wretched of the Earth. London: Penguin Books.

Foucault, M. (2002). Vigilar y castigar. Nacimiento de la prisión. Buenos Aires: Siglo XXI.

Gregory, D. (1998). Geographical Imaginations. London: Blackwell Publishers.

Grosz, E. (1995). Space, time and pervertion: Essays on the politics of bodies. London: Routledge.

Harvey, D. (1995). The condition of postmodernity: an enquiry into the origins of cultural change. Cambridge, MA: Blackwell Publishers.

Heiddegger, M. (1951). El ser y el tiempo. México: Fondo de Cultura Económica.

Jameson, F. (1991). El posmodernismo o la lógica cultural del capitalismo avanzado. Barcelona: Paidós.

Joyce, J. (1997). Ulises. Vol. I y II. Buenos Aires: CS.

Lacan, J. (1992). Lecturas de psicoanálisis. Freud, Lacan. Buenos Aires: Paidós.

Latour, B. (1993). We have never been modern. Hassocks: Harvester Editions.

Lefebvre, H. (1991). The production of space. Oxford and Cambridge, MA: Blackwell Publishers.

Livingston, I. (1997). Arrow of Chaos. Romanticism and Posmodernity. Minneapolis: Minnesota University Press.

Maspero, F. (1994). Roissy Express: a journey through the Paris suburbs. London: Verso.

Massey, D. (2005). La filosofía y política de la espacialidad: algunas consideraciones. En L. Arfuch (comp.). Pensar este tiempo. Espacios, afectos, pertenencias. Buenos Aires: Paidós.

Moreiras, A. (2001). The exhaustion of difference. The politics of Latin American cultural studies. Durham: Duke University.

Moretti, F. (1998). Atlas of the European novel 1800-1900. London: Verso.

Nietzsche, F. (2003). La genealogía de la moral. Madrid: Tecnos.

Ortega, N. (1987). Geografía y cultura. Madrid: Alianza Universidad.

Ortega, J. (2000). Los horizontes de la geografía. Teoría de la geografía. Barcelona: Ariel. 
Pile, S. (1995). Mapping the Subject. New York: Routledge Editions.

Prendergast, C. (1992). Paris and the Nineteenth Century. Oxford: Blackwell Publishers.

Quaini, M. (1981). Marxismo y geografía. Barcelona: Oikos-Tau.

Said, E. (1985). Orientalism. London: Penguin Books.

Santos, M. (1990). Por una geografía nueva. Madrid: Espasa Universidad.

Serrés, M. (1994). Atlas. Madrid. Editorial Cátedra.

Soja, E (1996). Thridspace, journeys to Los Angeles and other real and imagined places. Oxford and Cambridge MA: Blackwell Publishers.

Spivak, G. (2000). A critique of postcolonial reason: toward a history of the vanishing present. Cambridge, MA: Harvard University Press.

Thrift, N. (1996). Spatial Formations. London: Sage Publications.

Thrift, N. (2008). Non representacional theory. New York and London: Routledge Editions.

Thrift, N. \& Crang, M. (2000). Thinking Space. London: Routledge Editions.

Unwin, T. (1995). El lugar de la geografía. Madrid: Cátedra.

Virilio, P. (1997). Open Sky. London: Verso.

Wittgenstein, L. (1961). Tractatus Logico-Philosophicus. London: Routledge Editions.

Recepción: 9 de abril de 2012

Evaluación: 4 de octubre de 2012

Aprobación: 20 de junio de 2013

\begin{tabular}{l|l}
\hline 174 & Miguel Ángel Silva
\end{tabular} 